\title{
Human health sciences-From cultivation to utilization of medicinal plants
}

\author{
Fumio Ikegami*, Yan Wang, Maya Kaneko, Megumi Sumino, Satoru Tsukagoshi
}

Center for Environment, Health and Field Sciences, Chiba University, Kashiwa, Japan;

"Corresponding Author: ikegami@faculty.chiba-u.jp

Received 12 January 2012; revised 20 February 2012; accepted 13 March 2012

\section{ABSTRACT}

The aim of this review is to recognize the ability of plants used as food and medicine for our health care. From this point of view, we have studied economical production techniques of medicinal plants and vegetables that have physiological functions such as disease prevention, health maintenance and improvement of physical function. We revealed the suitable cultivation techniques such as the long-term freezing seed storage, and systematic and efficient seedling production of Swertia japonica in the future domestication in Japan. We have also studied the development of a new and friendly product for preparing decoction of Kampo medicine (Japanese traditional medicine) to utilize medicinal plants effectively. It was possible that the decoction of some Kampo medicines in a microwavable container could be carried out in substitution for a common method. This study revealed that the improvement of decoction method of Kampo medicine might contribute to conserve the energic or natural resources, especially medicinal plants of crude drugs in comparison with the conventional way. Moreover, the re-evaluation of some vegetables such as Japanese radish and carrot in terms of the suitability as materials for "Yakuzen", and creating and producing of newly low potassium tomatoes for improving the quality of life (QOL) of dialysis patients and potassium restricted patients were also studied by focusing traditional and local vegetables. Some local cultivars containing stronger flavor and taste with higher amount of functional constituents are suitable for our health care than $F_{1}$ (first filial generation) cultivars. Our research will give feedback each other by cross cutting way, and human health science from the cultivation to utilization of medicinal plants and vegetables will be important and needed for our healthy and comfortable life in the future.

Keywords: Kampo Medicine; Yakuzen; Medicinal Plant; Functional Vegetable; Low Potassium Tomato

\section{INTRODUCTION}

To ensure better health and environment is one of the major issues in the 21 st century and then the important challenges have been faced. Efforts are underway to develop a new academic discipline called "human health sciences". The discipline incorporates philosophies of Oriental medicine and aims at maintaining or improving our quality of life (QOL) through a variety of trials. To clarify the effect of not only providing medical care using traditional medicine, traditional food products and functional plants, but also farming or horticultural activity on people's mind and bodily function is our great concern.

In recent years there has been an increase in the number of people in Japan suffering from so-called "lifestyle-related diseases" such as hypertension, diabetes, hyperlipidemia and obesity, as a consequence of changes in people's lifestyles such as adopting Western eating habits and engaging in less exercise. The rapid spread of visceral fat obesity has become an issue in particular, and when this is compounded by risk factors for arteriosclerosis such as hyperlipemia and hypertension, it can easily give rise to serious and potentially fatal illnesses such as angina pectoris, myocardial infarctions and brain infarctions. This condition is known as metabolic syndrome. Therefore, as well as the treatment by early diagnosis (secondly prevention), improvement of the lifestyle itself and the environment concerned with lifestyle (primary prevention) is emphasized nowadays [1].

While the concepts of diseases such as hyperlipemia or obesity do not inhere in Kampo medicine, there are nevertheless many prescriptions for dealing with those symptoms in it [2]. It is possible to maintain our health and prevent lifestyle-related diseases by enhancing our natu- 
ral healing ability and gastrointestinal function through the skilled use of Kampo medicine. In addition, crude drugs such as ginger, dioscorea rhizome (Dioscorea japonica or D. batatas) and jujube (Ziziphus jujube) are regarded as Yakuzen ingredients [3], and they are as well as popular ones for our daily meal. Thus, improvement of our dietary life is also important by utilizing Yakuzen theory.

Yakuzen is a form of medicinal cooking that combines food and traditional medicines, based on theories of Oriental medicine such as the yin-yang theory and the fivephase theory (Table 1) [3]. Yakuzen meals are prepared using in-season ingredients, crude drugs and foodstuffs matched to one's physical constitution and particular symptoms (patient's "sho" in Japanese or "Kampo diagnosis") [2]. The philosophies governing Yakuzen are "food as medicine" and "shindo fuji". In Japan and China, "food as medicine" is derived from the view that since medicine and food share a common origin, food is to be regarded not only as a source of nutrients, but also as a nurturing and restorative element like medicine. Shindo fuji is derived from a belief that human beings ought to eat foods in season from the land where they were born and raised since they cannot be separated from that place. From these backgrounds, the research in economical production techniques of medicinal plants or foods used as medicine and Yakuzen foodstuffs becomes more important.

This paper presents our attempts to produce medicinal plants for Kampo medicine using effective production techniques, and to develop a new decoction method of Kampo medicine for convenient uses. The evaluation of some local cultivars of vegetables, and the approaches to create and produce low potassium tomato fruits as a new functional vegetable for Yakuzen dishes are also described.

\section{RESULTS AND DISCUSSION}

\subsection{Producing Medicinal Plants Using Effective Production Techniques}

Kampo is a general term for the unique system of traditional medicine originally developed in Japan under the influence of traditional Chinese medicine (TCM). Recently Kampo medicines (Japanese traditional medicine) have been used by more than $86 \%$ of Japanese doctors since Kampo products were mostly included under the coverage of the public health insurance system in 1976 $[2,4]$. Kampo treatment places an emphasis on normalizing the distortion of mind and body in patients and improving QOL rather than curing the local disease. Thus, in parallel with the increase of chronic, lifestyle-related and complex diseases such as high blood pressure, lipid abnormality symptom and diabetes, patients have increasingly turned to Kampo treatment.

There are many kinds of medicinal plants that are used as folk medicine or the source of Kampo formulae such as kakkonto and shosaikoto [5-7]. Kampo formulae consist of several crude drugs; most of them are plant origin and have been screened out through many years of use. At present, 172 kinds of crude drugs are listed on the Japanese Pharmacopoeia (16th ed., 2011) [8], and more than $80 \%$ of the resources are the imports from China. However, nature resources in China are limited and agricultural production area is gradually declining in recent years [9]. Moreover, Chinese domestic demand on crude drugs is growing and personnel expenses are increasing. These situations influenced the price of crude drugs and it will be difficult to acquire the natural resources that are

Table 1. Five fundamental elements in nature and their properties.

\begin{tabular}{|c|c|c|c|c|c|}
\hline Phase & $\begin{array}{l}\text { Parenchymatous } \\
\text { viscera }\end{array}$ & Main function & $\begin{array}{l}\text { Hollow } \\
\text { viscera }\end{array}$ & Flavor & Function of flavor \\
\hline Wood & Liver & $\begin{array}{l}\text { Stabilizing mental activities, Storing } \\
\text { blood, Supplying nutrients to the whole } \\
\text { body, Detoxicating }\end{array}$ & Gallbladder & Sour & $\begin{array}{l}\text { Contracting the body (lemon, vinegar, etc). Too much } \\
\text { intake damages sleen and stomach. }\end{array}$ \\
\hline Fire & Heart & $\begin{array}{l}\text { Circulating blood, Adjusting the rhythm } \\
\text { of sleep and waking status }\end{array}$ & $\begin{array}{c}\text { Small } \\
\text { intestine }\end{array}$ & Bitter & $\begin{array}{l}\text { Controlling excitation and palpitation (burdock, } \\
\text { gourd, etc). Too much intake damages lung. } \\
\text { Unsuitable for Yin-fluid deficiency. }\end{array}$ \\
\hline Earth & Spleen & $\begin{array}{l}\text { Digesting and absorbing foods, } \\
\text { Maintaining patency of blood vessels }\end{array}$ & Stomach & Sweet & $\begin{array}{l}\text { Nourishing the body (pumpkin, sweet potato, etc). } \\
\text { Too much intake damages kidney (causes swellen } \\
\text { and heat). }\end{array}$ \\
\hline Metal & Lung & $\begin{array}{l}\text { Inhaling ki by breathing and spreading } \\
\text { throughout the body }\end{array}$ & $\begin{array}{c}\text { Large } \\
\text { intestine }\end{array}$ & Pungent & $\begin{array}{l}\text { Promoting the circulation of ki (ginger, leek, Japanese } \\
\text { radish, etc). Too much intake damages liver. } \\
\text { Unsuitable for Yin-fluid deficiency. }\end{array}$ \\
\hline Water & Kidney & $\begin{array}{l}\text { Controlling growth, development and } \\
\text { urogenous function, Forming and } \\
\text { maintaining bones and teeth }\end{array}$ & Bladder & Salty & $\begin{array}{l}\text { Making the body pliant (salt, sea tangle, etc.). Too } \\
\text { much intake damages heart (causes hypertension). }\end{array}$ \\
\hline
\end{tabular}


necessary in Japan. Therefore, the increase of the domestic production of original plant resources for crude drugs becomes a pressing matter, and technical researches to produce them in high quality are in progress. For example of Glycyrrhiza, a fine strain was selected and cultivated by hydroponic production system or in plastic tubes [10-12].

Developing cultivation techniques to increase the yield and raise the medicinal component of medicinal plants, as well as breeding cultivars with genetic superiority in yield and medicinal component, are important for the future development of Kampo medicine and the business of health care.

We currently conduct research on the cultivation techniques and medicinal component of the plants such as purple perilla (Perilla frutescens), bupleurum (Bupleurum falcatum), Japanese green gentian (Swertia japonica) and Japanese angelica (Angelica acutiloba). This research involves using drip fertigation technique on substrate mixed with thermophilic bacteria [13]. The growth and the component content of these plants were affected by kinds of substrate and nutrient solution, and the adequate conditions to produce the plants are gradually clarified.

As part of the research on the cultivation of medicinal plants, the research was conducted on the effective production of $S$. japonica, a biennial plant widely grown in the wild and used as a traditional stomachic medicine for long time in Japan. The Japanese Pharmacopoeia defines that the principal medicinal component of S. japonica is swertiamarin and the plants must contain it not less than $2 \%$ as dry matter basis when the plants are used as a crude drug [8].

$S$. japonica is currently cultivated only in Nagano and Kouchi prefecture, where the $76 \%$ and $24 \%$ of the total yield in Japan was obtained, respectively [14]. There are very few previous reports related to the cultivation of $S$. japonica and most of those are concerned with the reproduction of the plant, such as the promotion of seed germination, the examination of the tissue culture. In other words, there is little information about the relationship of the varieties and growth conditions to the yield and medicinal component.

As stable seed supply is necessary for effective production, the study to clarify the effect of long-term freezing storage of $S$. japonica seeds on germination, yield and swertiamarin content of the seedling was carried out [15]. The seeds were successively collected for years by the conventional way and stored at $-20^{\circ} \mathrm{C}$. The germination percentage affected by seed storage period, but there were no correlation between the percentage and the period (Figure 1). In addition, there was no correlation between plant dry weight and seed storage period. Although it was revealed that long-term preservation might lead to a decline in swertiamarin content, all plants contained more than $2 \%$ swertiamarin and satisfied the criteria as a crude drug by HPLC analysis (Table 2). Therefore, the seed viability of $S$. japonica can be maintained for around 13 years by freezing at $-20^{\circ} \mathrm{C}$ without affecting on dry matter yield and quality as a crude drug. This result would contribute to the constraction of seedling production system and the system can separate the field cultivation from the task of raising seedlings, thereby mitigate the risk from disease in the field.

In order to bring about systematic and efficient seedling production, the rate and percentage of seed germination will need to be improved. To that end the effects of gibberellin treatment on the rate and percentage of germination were investigated. Both the germination percentage and rate increased by $12-24$ hours soaking in a gibberellin solution of $200 \mathrm{ppm}$ (Table 3) [16]. When seeds were soaked for a long period in a high-concentration

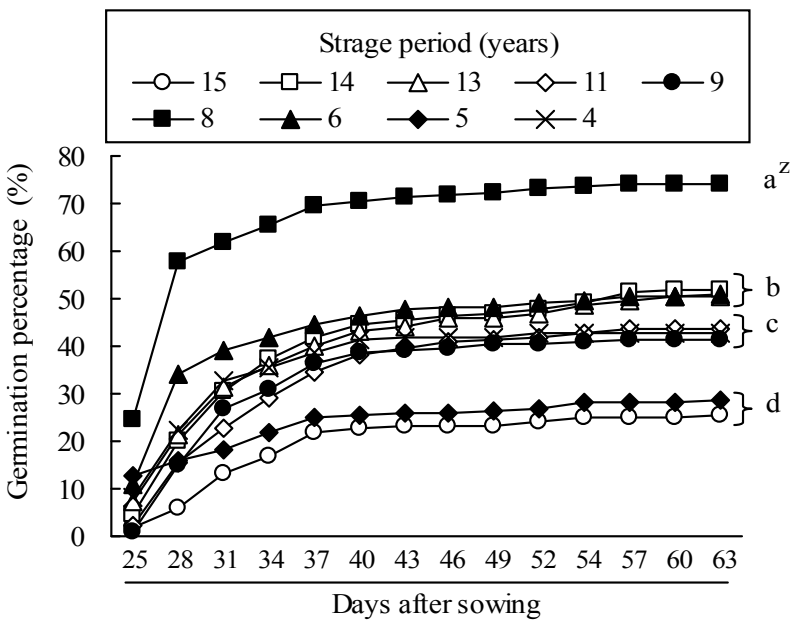

Figure 1. Effect of the period of freeze storage on germination of $S$. japonica seeds. ${ }^{\mathrm{z}}$ Different letters indicate significant difference by Tukey's multiple range test at $5 \%(n=4)$.

Table 2. Effect of the period of freeze storage on swertiamarin content of $S$. japonica seedlings.

\begin{tabular}{cc}
\hline Storage period (years) & Content $(\mathrm{mg} / \mathrm{g} \mathrm{DW})$ \\
\hline 13 & $33.1 \pm 10.3^{\mathrm{z}}$ \\
12 & $54.4 \pm 7.8$ \\
11 & $35.5 \pm 8.9$ \\
9 & $45.1 \pm 12.7$ \\
7 & $48.5 \pm 12.3$ \\
6 & $40.6 \pm 6.3$ \\
2 & $48.1 \pm 5.3$ \\
0 (conventional) & $44.9 \pm 14.2$ \\
\hline
\end{tabular}

${ }^{\mathrm{z}}$ Mean \pm Standard error $(\mathrm{n}=4)$. 
gibberellin solution, however, both the germination percentage and rate declined. These factors will come to serve as reference for cultivation techniques in the future domestication of medicinal plants in Japan.

The difference in medicinal component among strains or cultivars was also determined [17]. We could demonstrate that some unutilized strains of $S$. japonica contained higher swertiamarin than the cultivar used for commercial production (Table 4). These strains may contribute to the increase of swertiamarin production or the breeding of new cultivar. This result suggested that there would be some wild genetic resources which have superior characters. The production of vigorous transplant using the transplant culture system with artificial environment control may be effective to promote the growth after transplanting to the field in the second year.

We currently determine the effectiveness of production techniques developed for horticultural crops to increase the plant and component yield of other medicinal plants.

\subsection{Improvement of Decoction Method of Kampo Medicine to Conserve Natural Resources}

It is one of the great contributions to extract crude drugs of Kampo medicines efficiently for utilizing medicinal plants. The decoction method is described with respect to each Kampo formula in the classic book represented by "Shanghanlun" that was probably completed in the Han dynasty (206 BC-220 AD) and included diagnosis as well as treatment of acute febrile disease called "shanghan" [2]. In current Japan, an electric appliance with glass container or a ceramic one heated directly on fire is commonly used. Though it is difficult for old patients to accept expensive and fragile article, it is necessary to find a new decoction method and a new container.

We have studied the extraction efficiency of Kampo medicine, kakkonto, decocted in different containers in a microwave oven (Hitachi, MRO-DF6) and compared with the common method [18]. Kakkonto is popular and clinically used for the treatment of various feverish diseases such as common cold and inflammation. Daily dose of kakkonto contains 7 precious crude drugs of Pueraria root (8 g), Jujube (4 g), Ephedra herb (4 g), Glycyrrhiza $(2 \mathrm{~g})$, Cinnamon bark ( $3 \mathrm{~g})$, Peony root $(3 \mathrm{~g})$ and Ginger (1 g) [2].

We confirmed that authentic components of the decoction were ephedrine and pseudoephedrine in Ephedra herb, puerarin in Pueraria root, paeoniflorin in Peony root and glycyrrhizin in Glycyrrhiza by the HPLC method as well as 6-gingerol in Ginger and cinnamaldehyde in Cinnamon bark by the TLC method described in
Table 3. Effect of soaking in gibberellic acid (GA) on germination of $S$. japonica seeds.

\begin{tabular}{|c|c|c|c|}
\hline \multicolumn{2}{|c|}{ Treatment } & \multirow{2}{*}{$\begin{array}{c}\text { Germination } \\
\text { percentage }(\%)\end{array}$} & \multirow{2}{*}{$\begin{array}{c}\text { Germination rate } \\
(\%)\end{array}$} \\
\hline $\begin{array}{c}\text { GA concentration } \\
(\mathrm{ppm})\end{array}$ & $\begin{array}{l}\text { Soaking } \\
\text { time (hr) }\end{array}$ & & \\
\hline \multirow{3}{*}{0 (water) } & 12 & $84.3 \pm 1.1^{\mathrm{z}} \mathrm{ab}^{\mathrm{y}}$ & $56.3 \pm 1.6$ bcde \\
\hline & 24 & $82.0 \pm 2.1 \mathrm{ab}$ & $60.3 \pm 2.4 \mathrm{bcd}$ \\
\hline & 48 & $82.5 \pm 1.3 \mathrm{ab}$ & $53.0 \pm 2.4$ bcde \\
\hline \multirow{3}{*}{200} & 12 & $77.5 \pm 2.7 \mathrm{abc}$ & $64.5 \pm 2.4 \mathrm{ab}$ \\
\hline & 24 & $87.8 \pm 0.7 \mathrm{a}$ & $71.5 \pm 0.3 \mathrm{a}$ \\
\hline & 48 & $74.3 \pm 3.6 \mathrm{bc}$ & $51.0 \pm 6.8 \mathrm{cde}$ \\
\hline \multirow{3}{*}{400} & 12 & $74.3 \pm 2.2 \mathrm{bc}$ & $61.0 \pm 1.1 \mathrm{abc}$ \\
\hline & 24 & $59.3 \pm 4.8 \mathrm{de}$ & $48.5 \pm 4.0 \mathrm{e}$ \\
\hline & 48 & $48.8 \pm 4.1 \mathrm{e}$ & $19.8 \pm 4.5 \mathrm{~g}$ \\
\hline \multirow{3}{*}{600} & 12 & $67.8 \pm 2.4 \mathrm{~cd}$ & $48.8 \pm 2.2 \mathrm{de}$ \\
\hline & 24 & $38.3 \pm 6.2 \mathrm{f}$ & $26.7 \pm 3.9 \mathrm{f}$ \\
\hline & 48 & $51.0 \pm 4.6 \mathrm{e}$ & $36.5 \pm 4.4 \mathrm{f}$ \\
\hline \multirow{3}{*}{$\begin{array}{c}\text { Anova } \\
\text { (F value) }\end{array}$} & GA (G) & $34.2^{\mathrm{x}^{* * *}}$ & $39.1^{* * *}$ \\
\hline & Time $(\mathrm{H})$ & $14.0^{* * *}$ & $9.2^{* * *}$ \\
\hline & $\mathrm{G} \times \mathrm{H}$ & $9.4^{* * *}$ & $7.0^{* * *}$ \\
\hline
\end{tabular}

${ }^{\mathrm{z}}$ Mean \pm Standard error $(\mathrm{n}=4) ;{ }^{\mathrm{y}}$ Different letter within column indicate significant difference by Fisher's LSD at $5 \%,{ }^{x^{*}},{ }^{* * *}$ : Significant at $5 \%$ and $0.1 \%$, respectively.

Table 4. Difference of plant dry weight and swertiamarin content among strains and cultivars of $S$. japonica.

\begin{tabular}{ccccc}
\hline \multirow{2}{*}{ Strain and cultivar } & $\begin{array}{c}\text { Dry weight } \\
\text { (g/plant) }\end{array}$ & \multicolumn{2}{c}{ Swertiamarin content } \\
\cline { 3 - 5 } & 4 & $1.3 \pm 0.2^{\mathrm{z}}$ & $22.5 \pm 1.8$ & $28.9 \pm 4.6$ \\
& $14-\mathrm{mg} / \mathrm{g} \mathrm{DW})$ & $(\mathrm{mg} / \mathrm{plant})$ \\
\hline \multirow{2}{*}{ Strains } & $1.5 \pm 0.2$ & $18.7 \pm 2.8$ & $26.9 \pm 4.5$ \\
& 15-Haya & $1.5 \pm 0.2$ & $31.3 \pm 3.3$ & $46.8 \pm 8.9$ \\
& S-117 & $1.0 \pm 0.1$ & $33.9 \pm 1.5$ & $32.3 \pm 3.5$ \\
& Kanshoyou & $3.0 \pm 0.3$ & $14.6 \pm 1.7$ & $43.7 \pm 7.8$ \\
& Kanfuzan & $2.2 \pm 0.2$ & $21.4 \pm 0.5$ & $47.5 \pm 4.5$ \\
Cultivars & Mimaki-2-go & $2.0 \pm 0.4$ & $21.0 \pm 3.8$ & $41.8 \pm 2.0$ \\
& Mimaki-3-go & $2.0 \pm 0.5$ & $14.6 \pm 2.1$ & $26.8 \pm 4.6$ \\
\hline
\end{tabular}

${ }^{\mathrm{z}}$ Mean \pm Standard error $(\mathrm{n}=4)$.

the Japanese Pharmacopoeia [8]. Tannin content was also determined by the spectroscopic method [19].

When we decocted kakkonto in $600 \mathrm{~mL}$ water by a microwavable rice cooker (Skater, MWC-1, polypropyl- 
ene) or herb teapot (Hario, XCK-1000, glass) at $500 \mathrm{~W}$ for $30 \mathrm{~min}$, the yield of powdered extract was within the prescribed amount as well as that obtained by the common method. The all authentic components in the decoction prepared by a microwave oven in $600 \mathrm{~mL}$ water at $500 \mathrm{~W}$ were almost the same as those obtained by an electric decoction appliance (Hario, HMJ3-1000) in 500 $\mathrm{mL}$ water for $30 \mathrm{~min}$ (Table 5). The evaporation of moisture in a microwave oven was more than that of common method, so we used additional $100 \mathrm{~mL}$ water in a microwave oven. Thus, it is possible that the decoction of some Kampo medicines in a microwavable container could be carried out by heating at $500 \mathrm{~W}$ for $30 \mathrm{~min}$ in substitution for a common method, but we still need to improve a container suitable for the higher extraction efficiency to conserve the energic or natural resources.

We have also conducted the chemical analysis of the constituents in the residual crude drugs of shosaikoto by decocting twice in an electric decoction appliance (Hario, HMJ3-1000; Tochimoto, EK-SA10) [20]. Shosaikoto is popular and clinically used for the treatment of various feverish diseases such as common cold, pneumonia and liver disorder. Daily dose of shosaikoto contains 7 precious crude drugs of Bupleurum root $(7 \mathrm{~g})$, Pinellia tuber (5 g), Scutellaria root (3 g), Jujube (3 g), Ginseng (3 g), Glycyrrhiza (2 g) and Ginger (1 g) [2].

From our study, powdered extract from the second decoction of residual crude drugs of shosaikoto was $26 \%$ of that from the first decoction. Saikosaponin $b_{2}$ in the second decoction was $2.1 \mathrm{mg}$ comparable to the amount in the first decoction $(2.4 \mathrm{mg})$. Extraction efficiency of the other chemical constituents and factors that influence the extraction efficiency such as decoction time and water volume are now under consideration. Continuous study on the utilization of crude drugs, however, will be essential in the resource-saving environment.

\subsection{Evaluation of Some Local Cultivars of Japanese Radish and Carrot in terms of the Suitability as Materials for "Yakuzen" Dishes}

We conduct research on medicinal properties of vege- tables as Yakuzen ingredients, such as Japanese radish (Raphanus sativus) [21] and carrot (Daucus carota) [22] which are both a medicinal plant in Oriental medicine. To prepare Yakuzen dishes for the constitution or the symptom of each person, materials in season with appropriate properties and tastes play a vital role, and these properties and tastes are called "Sei-Mi" in the Yakuzen theory. "Sei-Mi" is composed of four natures (hot, warm, cool, cold) and five tastes (salty, bitter, sweet, pungent, sour) according to TCM, and each property and/or taste is considered to show its own functionality for human body (Table 1). Therefore, the materials for Yakuzen dishes are selected for the physical condition and constitution of each person. If the "Sei-Mi" concept can apply to vegetables, cultivar which has strong inherent flavor and taste with high functional constituents related to the property and taste would be defined to have strong "Sei-Mi," and thus the cultivar can be accounted to have high suitability as materials for Yakuzen dishes.

The inherent flavor and taste of current vegetable cultivars tend to become weak as a result of breeding which gives the priority to the easiness to eat for consumers, or the easiness to grow for growers, etc. In the case of carrot, most of all carrot cultivars nowadays are $F_{1}$ (first filial generation) with similar size and shape. In contrast, various cultivars that have various root shapes and colors were used in the time when the carrot production started domestically in Japan. And it was reported that the main constituents in the root varied depending on the cultivar with different root shapes or colors [23,24]. Consequently, it is expected that the flavor, the taste and the content of functional constituents also depends on the cultivars $[25,26]$. In other words, so-called local cultivars grown for many years may have been keeping the inherent flavor and taste, and some of them may be more suitable for Yakuzen dishes than current ones.

Suitability of Japanese radish cultivars for Yakuzen dishes was evaluated by sensory test, amounts of functional constituents related to the taste and functionality and principal component analysis [21]. One $\mathrm{F}_{1}$ cultivar and 18 local cultivars belonged to 11 local varietal groups was used (Table 6). Cultivars that were considered to possess many aptitudes as Yakuzen ingredients,

Table 5. Authentic components and extract contents in kakkonto decocted by the different methods.

\begin{tabular}{|c|c|c|c|c|c|c|c|c|}
\hline \multicolumn{3}{|c|}{ Decoction method } & \multirow{2}{*}{$\begin{array}{l}\text { Puerarin } \\
\text { (mg) }\end{array}$} & \multirow{2}{*}{$\begin{array}{l}\text { Paeoniflorin } \\
\text { (mg) }\end{array}$} & \multirow{2}{*}{$\begin{array}{l}\text { Glycyrrhizin } \\
\text { (mg) }\end{array}$} & \multirow{2}{*}{$\begin{array}{l}\text { Ephedrine } \\
\quad(\mathrm{mg})\end{array}$} & \multirow{2}{*}{$\begin{array}{l}\text { Pseudoephedrine } \\
(\mathrm{mg})\end{array}$} & \multirow{2}{*}{$\begin{array}{l}\text { Tannin } \\
(\mathrm{mg})\end{array}$} \\
\hline Appliance & Water volume & $\begin{array}{l}\text { Decoction } \\
\text { time }\end{array}$ & & & & & & \\
\hline Microwave oven \& Herb teapot & $600 \mathrm{~mL}$ & $30 \mathrm{~min}$ & $129.4 \pm 10.0^{z}$ & $59.5 \pm 2.4$ & $56.7 \pm 2.6$ & $18.0 \pm 1.0$ & $6.9 \pm 0.6$ & $53.7 \pm 3.1$ \\
\hline Microwave oven \& Rice cooker & $600 \mathrm{~mL}$ & $30 \mathrm{~min}$ & $121.8 \pm 3.5$ & $56.9 \pm 4.1$ & $56.9 \pm 6.2$ & $16.5 \pm 1.0$ & $6.1 \pm 0.3$ & $51.9 \pm 0.9$ \\
\hline Hario, HMJ3-1000 & $500 \mathrm{~mL}$ & $30 \mathrm{~min}$ & $116.5 \pm 14.6$ & $57.9 \pm 3.7$ & $59.4 \pm 6.3$ & $17.2 \pm 1.0$ & $6.1 \pm 0.5$ & $50.9 \pm 3.2$ \\
\hline
\end{tabular}

${ }^{\mathrm{z}}$ Mean $\pm \operatorname{SD}(\mathrm{n}=4)$. 
Table 6. Local varietal groups and local cultivars of daikon (Japanese radish, Raphanus sativus L.) and carrot (Daucus carota L.).

\begin{tabular}{|c|c|c|c|c|c|}
\hline Daikon Group & Daikon Cultivar & Abbreviation & Carrot Group & Carrot Cultivar & Abbreviation \\
\hline Miyashige $\mathrm{F}_{1}$ & Taibyo-so-butori & $\mathrm{MF}_{1}$ & $\mathrm{~F}_{1}$ & Kouyou-2-gou & $\mathrm{K} 2$ \\
\hline \multirow[t]{4}{*}{ Miyashige } & Miyashige & MM & & Chihama-5-sun & $\mathrm{C} 5$ \\
\hline & Aokubi-miyashige-marujiri & MB & & Purple Haze & $\mathrm{PH}$ \\
\hline & Shirokubi-miyashige-shirimaru & MW & 3 -sun & Tokinashi-3-sun & $\mathrm{T} 3$ \\
\hline & Gensuke & MG & 5 -sun & Tokinashi-5-sun & T5 \\
\hline \multirow[t]{2}{*}{ Nerima } & Okura & NO & & Shin-Kuroda-5-sun & SK5 \\
\hline & Miura & NM & & Shin-Ogata-5-sun & $\mathrm{SO} 5$ \\
\hline \multirow[t]{2}{*}{ Shogoin } & Shogoin & SS & & Hakata-Tokinashi-5-sun & HT5 \\
\hline & Kokufu & SK & & Super-Harumaki-5-sun & SH5 \\
\hline Horyo & Horyo & $\mathrm{H}$ & 8 -sun & Tokinashi-8-sun & $\mathrm{T} 8$ \\
\hline \multirow[t]{2}{*}{ Awa-bansei } & Awa-takuan & AA & Long orange & Senko-Futonaga & $\mathrm{SeF}$ \\
\hline & Misono & $\mathrm{AM}$ & & Senko-Onaga & $\mathrm{SeO}$ \\
\hline Shinshu-ji-daikon & Shinshu-ji-daikon & $\mathrm{Si}$ & & Kokubun-Senko-Onaga & $\mathrm{KSeO}$ \\
\hline \multirow[t]{2}{*}{ Tohoku-ji-daikon } & Kairyo-sendai & $\mathrm{TK}$ & & Super-Senko-1-Shaku & $\mathrm{SSeS}$ \\
\hline & Akasuji & TA & Danvers & Sapporo-Futo & $\mathrm{SaF}$ \\
\hline Shiro-agari & Wakayama & W & Kintoki & Honbeni-Kintoki & HK \\
\hline Moriguchi & Moriguti-hosonaga & M & Okinawa zairai & Shima-Ninjin & SN \\
\hline Ninengo & Suikomi-ninenngo & $\mathrm{N}$ & & & \\
\hline Minami-kyushu-ji-daikon & Sakurajima & $\mathrm{S}$ & & & \\
\hline
\end{tabular}

such as high in sweetness, high total soluble solid, amino acids (including glutamine) and isothiocyanate (the pungency component of Japanese radish) content [27], were distributed in the first quadrant of the graph (Figure 2). As a result, "Shinshu-ji-daikon" and "Shogoin" was considered to contain higher amount of functional ingredients. "Shinshu-ji-daikon" showed higher contents of sucrose, GABA and total amino acids, and isothiocyanate than the other cultivars. "Shogoin" (SS) also contained higher level of GABA and total amino acid than those of $\mathrm{F}_{1}$ cultivar. In conclusion, within the range of cultivars we used, "Shinshu-ji-daikon" (Si) was the most suitable material for Yakuzen dishes because it contained stronger taste and higher amount of functional ingredients (Figure 3 ).

Suitability of carrot cultivars for Yakuzen was also evaluated by the same concept as for Japanese radish, especially including volatile compounds content [22]. One $F_{1}$ cultivars and 16 local cultivars belonged to seven local varietal groups were used (Table 6). As a result of sensory test, three local cultivars ("Hakata-Tokinashi-5sun"; "HT5", "Kokubun-Senko-Onaga"; "KSeO" and "Sapporo-Futo"; "SaF") were considered to have proper

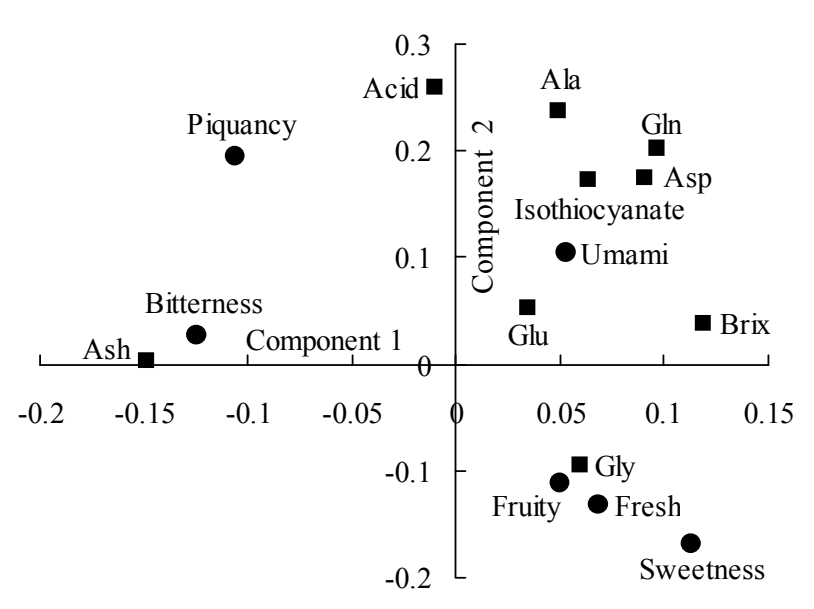

Figure 2. Two-dimensional scatter diagram of factor loading of daikon by principal component analysis. $\mathbf{m}, \bullet$ : data was derived by sensory test, chemical analysis and growth measurement, respectively.

characteristics for Yakuzen because of their strong taste (Table 7). And one of the $\mathrm{F}_{1}$ cultivars ("Chihama-5sun"; "C5") was also considered to be suitable, object cultivar "Kouyou-2-gou" ("K2") and these four cultivars 


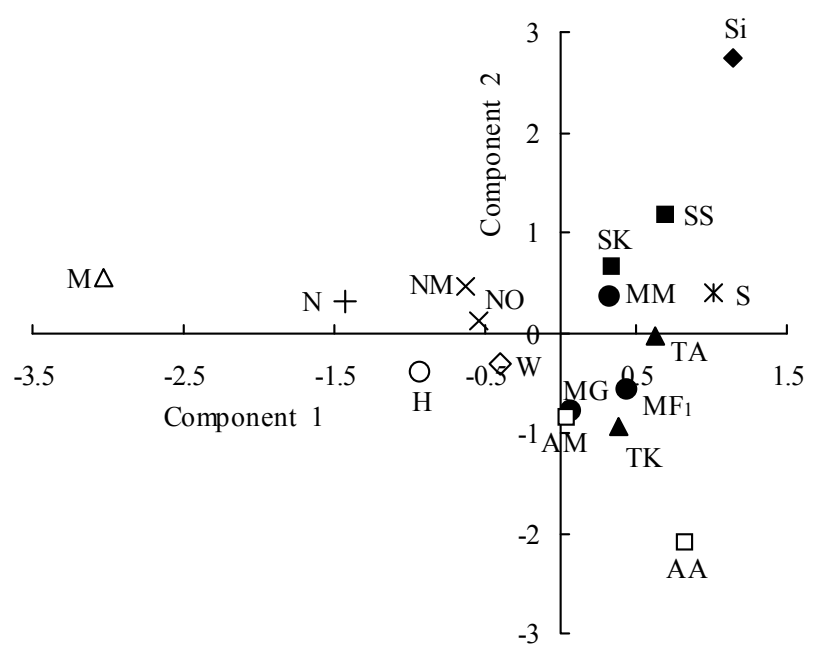

Figure 3. Two-dimensional scatter diagram of the principal component score of daikon cultivars. Abbreviations: See Table 6.

were evaluated in detail. Generally, selected four cultivars showed higher sourness, less sugar, higher ash and carotenoid content, and higher anti-oxidant activity than those of "K2" (Table 8). Amino acid contents of "KSeO" and "SaF" were ten and six times higher than those of "K2", respectively. On one hand, "K2" and "C5" could characterize to be sweet but less functional. On the other hand, "HT5", "KSeO" and "SaF" had complex taste and much functional constituents, although the factor loadings by principal component analysis were small. Besides, local cultivars had more volatile compounds than $F_{1}$ cultivars. It is widely known that smell greatly influences the taste of food. Besides, most of the volatile compounds are terpenoids such as monoterpenes or sesquiterpenes etc., and the composition differs from cultivars, from the data by the GC-MS analysis (Table 9). In conclusion, some local cultivars of carrot have stronger taste and more functional constituents than current F1 cultivars. "KSeO" and "SaF" were considered to be the most suitable material for Yakuzen dishes within the range of cultivars, because it showed strong flavor and taste with higher amount of functional constituents.

\subsection{Creating and Producing Low Potassium Tomatoes}

Consumers today demand higher safety and security for the food. Especially in the field of medical care, the

Table 7. Taste and characteristics of local cultivars evaluated by sensory test ${ }^{\mathrm{z}}$.

\begin{tabular}{|c|c|c|c|c|c|}
\hline \multirow{2}{*}{ Cultivar } & \multicolumn{3}{|c|}{ Taste } & \multirow{2}{*}{ Other characteristics ${ }^{\mathrm{y}}$} & \multirow{2}{*}{$\begin{array}{l}\text { Cultivars used for } \\
\text { further study }\end{array}$} \\
\hline & Strong carrot flavor & Sweet & Bitter, Acrid & & \\
\hline K2 & & $0^{x}$ & & Fresh, Fruity, Cosmetic & $\bullet$ \\
\hline $\mathrm{C} 5$ & ○ & $\circ$ & & Fresh and smooth & $\bullet$ \\
\hline $\mathrm{PH}$ & & & $\circ$ & Fresh and slightly hard, Potato-like & \\
\hline $\mathrm{T} 3$ & & & & Bamboo shoot-like, Weak taste, Porous & \\
\hline T5 & & $\circ$ & & Fresh and slightly hard & \\
\hline SK5 & & & & Cosmetic, Cinnamon-like & \\
\hline $\mathrm{SO} 5$ & $\circ$ & & & Smell of earth, Bamboo shoot-like & \\
\hline HT5 & ○ & & & Fresh and slightly hard & $\bullet$ \\
\hline SH5 & & & & Chestnut-like, Bamboo shoot-like & \\
\hline $\mathrm{T} 8$ & & & & Raw, Bamboo shoot-like & \\
\hline $\mathrm{SeF}$ & $\circ$ & & & Fresh and smooth, Potato-like, Fluffy (not soggy) & \\
\hline $\mathrm{SeO}$ & & & $\circ$ & Fresh and slightly hard, Dry, Potato-like & \\
\hline $\mathrm{KSeO}$ & $\circ$ & $\circ$ & & Kampo medecine-like, Fresh and smooth & $\bullet$ \\
\hline SSeS & & & & Sweet as dried persimmon, Dry & \\
\hline $\mathrm{SaF}$ & $\circ$ & & & Fresh and smooth, Fruity & $\bullet$ \\
\hline $\mathrm{HK}$ & & & $\circ$ & Fresh and smooth & \\
\hline $\mathrm{SN}$ & & & $\circ$ & Fresh and smooth, Chestnut-like & \\
\hline
\end{tabular}

${ }^{\mathrm{z}}$ Carrot samples were steamed at $100{ }^{\circ} \mathrm{C}$ for 5 minutes before the test; ${ }^{\mathrm{y}}$ The description of characteristics was identified by profile interview method; ${ }^{\mathrm{x}}$ The taste can be clearly felt. 
Table 8. Soluble solid, total sugar, carotenoid and ash content, and DPPH radical scavenging capacity of selected carrot cultivars.

\begin{tabular}{cccccc}
\hline Cultivar & Soluble solid (Brix \%) & Total sugar (g/100g FW) & Ash (mg/g DW) & $\begin{array}{c}\text { Carotenoid } \\
(\mathrm{mg} / 100 \mathrm{~g} \mathrm{FW})\end{array}$ & $\begin{array}{c}\text { DPPH radical scavenging } \\
\text { capacity }{ }^{\mathrm{y}}(\%)\end{array}$ \\
\hline $\mathrm{K} 2$ & $7.2 \pm 0.1^{\mathrm{x}} \mathrm{b}^{\mathrm{w}}$ & $7.4 \pm 0.2 \mathrm{a}$ & $308.2 \pm 14.7 \mathrm{bc}$ & $11.3 \pm 0.8 \mathrm{c}$ & $31.9 \pm 2.2 \mathrm{~b}$ \\
$\mathrm{C} 5$ & $7.5 \pm 0.1 \mathrm{~b}$ & $5.8 \pm 0.1 \mathrm{~b}$ & $279.3 \pm 6.3 \mathrm{c}$ & $20.2 \pm 1.6 \mathrm{~b}$ & $42.1 \pm 3.1 \mathrm{ab}$ \\
$\mathrm{HT} 5$ & $7.5 \pm 0.3 \mathrm{~b}$ & $4.9 \pm 0.3 \mathrm{c}$ & $381.3 \pm 19.4 \mathrm{ab}$ & $38.1 \pm 0.7 \mathrm{a}$ & $44.4 \pm 4.2 \mathrm{ab}$ \\
$\mathrm{KSeO}$ & $8.7 \pm 0.1 \mathrm{a}$ & $3.9 \pm 0.7 \mathrm{c}$ & $418.2 \pm 6.3 \mathrm{a}$ & $8.9 \pm 2.8 \mathrm{c}$ & $44.6 \pm 4.5 \mathrm{ab}$ \\
$\mathrm{SaF}$ & $9.2 \pm 0.2 \mathrm{a}$ & $3.7 \pm 0.3 \mathrm{c}$ & $418.9 \pm 14.0 \mathrm{a}$ & $23.0 \pm 1.6 \mathrm{~b}$ & $51.8 \pm 4.2 \mathrm{a}$ \\
\hline
\end{tabular}

${ }^{\mathrm{z}}$ Values are expressed as equivalent of $\beta$-carotene; ${ }^{\mathrm{y}}$ Capacity $(\%)=\left(\mathrm{A}_{\text {Bank }}-\mathrm{A}_{\text {Sample }}\right) / \mathrm{A}_{\text {Blank }} \times 100 ;{ }^{\mathrm{x}} \mathrm{Mean} \pm \operatorname{Standard}$ error $(\mathrm{n}=6) ;{ }^{\mathrm{w}}$ Different letter within the column indicates significant difference by Tukey's multiple range test at $5 \%$ level.

Table 9. Composition of major volatile compounds of carrot cultivars.

\begin{tabular}{|c|c|c|c|c|c|c|c|c|c|c|c|c|}
\hline \multirow{2}{*}{ No. } & \multirow{2}{*}{$\begin{array}{c}\mathrm{RT} \\
(\mathrm{min})\end{array}$} & \multirow{2}{*}{ Compound } & \multicolumn{10}{|c|}{ Peak area $\%^{z}$} \\
\hline & & & $\mathrm{K} 2$ & $\mathrm{C} 5$ & $\mathrm{PH}$ & SK5 & HT5 & SH5 & $\mathrm{T} 8$ & $\mathrm{KSeO}$ & $\mathrm{SaF}$ & HK \\
\hline 1 & 9.85 & $\alpha$-pinene & & & & 2.2 & 1.8 & 0.6 & 0.6 & 1.1 & 0.5 & 0.5 \\
\hline 2 & 10.79 & camphene & & & & 0.1 & & & 0.3 & & & \\
\hline 3 & 11.28 & sabinene & & & & & & & & & & 0.5 \\
\hline 4 & 11.71 & $\beta$-pinene & & & 0.5 & 1.4 & 1.6 & 0.3 & 0.4 & 1.5 & 2.0 & 2.3 \\
\hline 5 & 11.93 & $\alpha$-phellandrene & & & & 0.1 & 0.1 & 0.3 & 0.2 & 0.1 & nd & \\
\hline 6 & 12.74 & $\beta$-myrcene & & & & 0.3 & 0.3 & 0.2 & 0.3 & 0.9 & 0.4 & 0.15 \\
\hline 7 & 13.01 & $\alpha$-terpinene & & & & 0.1 & & 0.1 & 0.1 & 0.1 & 0.2 & \\
\hline 8 & 13.04 & $\alpha$-thujene & & & & & & & & & 0.2 & \\
\hline 9 & 13.92 & limonene & & & 0.6 & 1.1 & 0.6 & 0.7 & 0.9 & 0.9 & 1.2 & 0.6 \\
\hline 10 & 14.27 & $\beta$-phellandrene & & & & 0.1 & & & & & 0.1 & \\
\hline 11 & 14.61 & $\beta$-ocimene & & & & & & & & 3.8 & 0.0 & 0.3 \\
\hline 12 & 15.15 & $\gamma$-terpinene & & 0.9 & 1.1 & 3.5 & 4.7 & 3.0 & 5.8 & 5.3 & 10.0 & 0.8 \\
\hline 13 & 15.99 & $\rho$-cymene & & & & 0.5 & 0.3 & 0.2 & 0.3 & & 0.6 & \\
\hline 14 & 16.33 & terpinolene & 13.0 & 13.3 & 12.5 & 20.6 & 14.7 & 22.2 & 22.5 & 26.3 & 31.3 & 16.6 \\
\hline 15 & 25.29 & bornyl acetate & 1.1 & 3.2 & 2.2 & 2.5 & 1.5 & 0.6 & 6.2 & 4.0 & 2.3 & 1.8 \\
\hline 16 & 25.96 & $\beta$-caryophyllene & 18.1 & 8.5 & 10.7 & 24.6 & 24.9 & 40.7 & 5.4 & 7.8 & 22.0 & 5.4 \\
\hline 17 & 27.36 & neryl acetate & 0.1 & & & 0.4 & 0.4 & 0.3 & 0.3 & 6.2 & 0.3 & 1.5 \\
\hline 18 & 28.04 & $\alpha$-caryophyllene & 1.7 & 0.8 & 0.9 & 1.3 & 1.3 & 2.1 & 0.2 & 1.0 & 0.9 & 0.8 \\
\hline 19 & 29.08 & germacrene d & 0.5 & 1.3 & 0.5 & & & 0.3 & 0.2 & & 0.3 & \\
\hline 20 & 29.09 & $\alpha$-zingiberene & & & & 0.5 & 0.3 & & & 1.2 & & \\
\hline 21 & 29.24 & $\beta$-bisabolene & 1.3 & 0.8 & 0.9 & 1.1 & 1.0 & 1.0 & 1.5 & 0.9 & 1.5 & 0.6 \\
\hline \multirow[t]{3}{*}{22} & 29.37 & $\beta$-himachalene & 1.9 & 1.7 & 0.9 & 0.7 & 3.3 & 0.4 & 0.4 & 10.0 & 3.3 & 2.4 \\
\hline & & Others & 62.4 & 69.4 & 69.2 & 38.8 & 43.3 & 27.0 & 54.2 & 29.0 & 22.9 & 65.7 \\
\hline & & No. of Peaks & 10.7 & 11.0 & 12.3 & 23.0 & 15.5 & 19.0 & 23.0 & 19.0 & 21.7 & 14.7 \\
\hline
\end{tabular}

${ }^{\mathrm{z}}$ Values are means of 3 samples, and blank means the compound was not detected. 
vegetables with lower concentrations of toxic or harmful substances are strongly demanded for patients in the face of a particular disease as well as the safety and security. In order to meet those demands and to raise the QOL of many patients, producing crops with desirable characteristics is considered to be important. An organic coordination with researchers in various scientific fields should be necessary to meet both the patients' and health care professionals' needs and to explore the way for patientcentered medicine.

In recent years, the number of patients with diabetes inceases, and they must receive dialysis as a result of development into complications of kidney diseases. Dialysis patients and other patients with kidney dysfunction are given the diet treatment, and they are restricted potassium (K) intake less than $1500 \mathrm{mg} /$ day. Because vegetables and fruits usually contain much potassium, the patients require the fruits and vegetables with low potassium content.

We specifically conduct research to establish the production method for tomato (Solanum lycopersicum) fruits with low potassium content [28]. This research will enable dialysis patients and others with kidney dysfunction to eat fresh tomato and will improve in their QOL.

We first attempted to reduce the fruit potassium content by restricting the amount of potassium supply to the plant. Single cluster tomatoes (cv. Ai-chan, midi plum type) were hydroponically cultivated at $1 \mathrm{me} / \mathrm{L}$ of potassium in the nutrient solution. Then, potassium fertilizer was withdrawn from the nutrient solution after the flowering stage. The fruit potassium content decreased, accounting for $75 \%$ of the control (continuous $4 \mathrm{me} / \mathrm{L}$ of potassium supply), without any adverse effect on fruit weight and soluble solid content (Table 10). On the other hand, total potassium uptake was $8 \%$ of the control. In this attempt, plant had only 1 fruit cluster, and then potassium might be translocated to the fruit intensively. Thus, plant was allowed to emerge 3 fruit clusters in the next attempt to distribute potassium among 3 clusters and decrease the quantity of translocation to each cluster.

As a result, potassium content was reduced to $40 \%$ of control in cv. Ai-chan, but $60 \%$ in Frutica. According to the fruit taste, acidity markedly decreased in cv. Ai-chan (Table 11). One of the most important problems is that the fruit potassium become lower, the fruit acidity is liable to be lower. We should examine the cultivating method further to improve the sugar content, acidity and the other characteristics concerning to the taste.

\section{CONCLUSION}

In the ancient past, people used many plants as means for obtaining medical care. They would pick plants out from nature in hope of therapeutic effect to cool a fever, to relieve pain or to suppress inflammation. Through trial and error these plants came to be used more formally as medicines. Although the chemical-based medicine has come to predominate nowadays, they are not necessarily panaceas. Therefore, together with progress being made in medical care and the life sciences, Kampo medicine and other crude drugs made from natural ingredients, and vegetables with highly nutritional functions are into the limelight. Moreover, the functionality of popular foodstuffs such as garlic, buckwheat, soybeans and green tea has being realized again, and thus the use of such plants for lifestyle-related diseases is expected to spread further.

From our study, the possibility of effective production of medicinal plants and foods with high functional ingredients becomes clear by developing cultivation techniques. The results will enhance the effect of treatment by not only Kampo medicines but also Yakuzen dishes. Furthermore, local cultivars that have been grown at restricted area will be spotlighted and re-evaluated for our health maintenance. So as to select the cultivars, growers must obtain the philosophy of Oriental medicine and what property of plant material is desired from professionals. If foods become more functional by using those materials, people can prevent lifestyle-related diseases in particular and disease will be less complicated and easily cured. The effective use of plant materials by considering extraction efficiency will become essential in the future. Thus, the research must be closely coordinated each other and the integration of "food," "agricultural" and "environmental" sciences incorporating philosophies of Oriental medicine is the new academic field of "human health sciences," which embodies humanity's knowledge about "health."

\section{ACKNOWLEDGEMENTS}

We would like to thank all of our co-workers whose names appear in the references for their dedication, intellectual contributions, and hard

Table 10. Effect of potassium (K) supply on the fruit $\mathrm{K}$ content and total $\mathrm{K}$ uptake.

\begin{tabular}{|c|c|c|c|c|c|}
\hline K supply & Fruit weight (g/fruit) & $\begin{array}{c}\text { K content } \\
(\mathrm{mg} / 100 \mathrm{~g} \mathrm{FW})\end{array}$ & Soluble solid (\%) & Titratable acid ${ }^{\mathrm{z}}(\%)$ & Total K uptake (g/plant) \\
\hline 4 me/L K (control) & $42.3 \mathrm{a}^{\mathrm{y}}$ & $202 \mathrm{a}$ & $7.4 \mathrm{a}$ & $0.56 \mathrm{a}$ & $5.74 \mathrm{a}$ \\
\hline $1 \mathrm{me} / \mathrm{L} \mathrm{K}$ and withdrawal & $41.8 \mathrm{a}$ & $152 \mathrm{~b}$ & $6.8 \mathrm{a}$ & $0.42 \mathrm{~b}$ & $0.46 \mathrm{~b}$ \\
\hline
\end{tabular}

${ }^{\mathrm{z}}$ Values are equivalent of citric acid; ${ }^{\mathrm{y}}$ Different letter within the column indicates significant difference by $\mathrm{T}$ test at $5 \%$ level $(\mathrm{n}=6-8)$. 
Table 11. Effect of $\mathrm{K}$ supply on the fruit $\mathrm{K}$ content and fruit quality of 4 medium tomato cultivars grown in DFT in autumn.

\begin{tabular}{|c|c|c|c|c|c|c|c|}
\hline \multirow{2}{*}{ K supply } & \multirow{2}{*}{ Cultivar } & \multirow{2}{*}{$\begin{array}{l}\text { No. of fruit } \\
\text { cluster }\end{array}$} & \multirow{2}{*}{$\begin{array}{l}\text { Fruit weight } \\
\text { (g/fruit) }\end{array}$} & \multicolumn{2}{|c|}{$\mathrm{K}$ content } & \multirow{2}{*}{$\begin{array}{c}\text { Soluble solid } \\
\text { (\%) }\end{array}$} & \multirow{2}{*}{$\begin{array}{c}\text { Titratable acid } \\
(\%)\end{array}$} \\
\hline & & & & $(\mathrm{mg} / 100 \mathrm{~g} \mathrm{FW})$ & (mg/fruit) & & \\
\hline \multirow{6}{*}{$\begin{array}{l}\text { Continuous } 4 \\
\text { me/L K (control) }\end{array}$} & \multirow{4}{*}{ Ai-chan } & 1 & $34.9 \pm 0.8^{y}$ & $249 \pm 6$ & $70 \pm 4$ & $7.9 \pm 0.1$ & $0.72 \pm 0.02$ \\
\hline & & 2 & $39.6 \pm 1.3$ & $248 \pm 7$ & $83 \pm 4$ & $8.1 \pm 0.2$ & $0.67 \pm 0.02$ \\
\hline & & 3 & $43.7 \pm 1.6$ & $231 \pm 7$ & $87 \pm 3$ & $7.6 \pm 0.1$ & $0.67 \pm 0.02$ \\
\hline & & 1 & $38.5 \pm 2.5$ & $210 \pm 16$ & $77 \pm 7$ & $7.4 \pm 0.1$ & $0.46 \pm 0.06$ \\
\hline & \multirow[t]{2}{*}{ Frutica } & 2 & $37.5 \pm 2.7$ & $194 \pm 10$ & $69 \pm 4$ & $7.6 \pm 0.1$ & $0.49 \pm 0.01$ \\
\hline & & 3 & $49.3 \pm 1.7$ & $174 \pm 8$ & $83 \pm 5$ & $7.7 \pm 0.2$ & $0.44 \pm 0.01$ \\
\hline \multirow{6}{*}{$\begin{array}{l}1 \mathrm{me} / \mathrm{L} \mathrm{K} \text { and } \\
\text { withdrawal }\end{array}$} & \multirow{4}{*}{ Ai-chan } & 1 & $31.3 \pm 1.4$ & $105 \pm 4$ & $30 \pm 1$ & $7.7 \pm 0.0$ & $0.38 \pm 0.01$ \\
\hline & & 2 & $40.0 \pm 1.2$ & $98 \pm 3$ & $34 \pm 1$ & $6.9 \pm 0.1$ & $0.39 \pm 0.01$ \\
\hline & & 3 & $42.7 \pm 1.1$ & $82 \pm 5$ & $32 \pm 3$ & $7.0 \pm 0.2$ & $0.36 \pm 0.01$ \\
\hline & & 1 & $38.8 \pm 1.1$ & $147 \pm 5$ & $54 \pm 3$ & $6.9 \pm 0.2$ & $0.39 \pm 0.01$ \\
\hline & \multirow[t]{2}{*}{ Frutica } & 2 & $38.0 \pm 0.8$ & $127 \pm 6$ & $47 \pm 2$ & $7.4 \pm 0.2$ & $0.4 \pm 0.01$ \\
\hline & & 3 & $45.2 \pm 4.1$ & $126 \pm 5$ & $51 \pm 4$ & $6.9 \pm 0.1$ & $0.39 \pm 0.01$ \\
\hline ANOVA & \multicolumn{2}{|c|}{ K supply (K) } & 0.001 & $<0.001$ & $<0.001$ & $<0.001$ & $<0.001$ \\
\hline \multirow[t]{6}{*}{ (P value) } & \multicolumn{2}{|c|}{ Cultivar (C) } & $<0.001$ & $<0.001$ & 0.011 & 0.009 & $<0.001$ \\
\hline & \multicolumn{2}{|c|}{ No. of fruit cluster $(F)$} & $<0.001$ & 0.001 & 0.014 & 0.037 & $<0.001$ \\
\hline & \multicolumn{2}{|c|}{ Interaction $(\mathrm{K} \times \mathrm{C})$} & $<0.001$ & $<0.001$ & $<0.001$ & 0.006 & $<0.001$ \\
\hline & \multicolumn{2}{|c|}{$(\mathrm{K} \times \mathrm{F})$} & 0.140 & 0.054 & 0.297 & 0.779 & $<0.001$ \\
\hline & \multicolumn{2}{|c|}{$(\mathrm{C} \times \mathrm{F})$} & 0.001 & 0.019 & 0.002 & $<0.001$ & 0.005 \\
\hline & \multicolumn{2}{|c|}{$(\mathrm{K} \times \mathrm{C} \times \mathrm{F})$} & 0.419 & 0.017 & 0.249 & $<0.001$ & 0.019 \\
\hline
\end{tabular}

${ }^{\mathrm{z}}$ Values are equivalent of citric acid; ${ }^{\mathrm{y}}$ Mean \pm Standard error $(\mathrm{n}=7)$.

work. Our work was partially supported by Grants-in Aid from the Ministry of Education, Culture, Sports and Technology of Japan, and by Research Grants from the Uehara Memorial Foundation, Japan.

\section{REFERENCES}

[1] Ministry of Health, Labour and Welfare (2009) Health, labour and welfare report 2008-2009, Part 2, No. 62.

[2] Japan Society for Oriental Medicine. (2005) Introduction to KAMPO. Elsevier Japan, Tokyo.

[3] Tokui, N., Minari, Y., Zhang, Z.L. and Guo, X. (2003) Yakuzen to Chuigaku. Kenpakusha, Tokyo, 2-32.

[4] Akiba, T. (2010) History of Kampo extracts for Medical use. Kampo Medicine, 61, 881-888.

[5] Ikegami, F. (2001) Herbal drugs in Kampo medicines in present-day Japan. Emerging drugs Vol. 1: Molecular aspects of Asian medicines. PJD Publication Ltd., New Hyde Park, 489-507.

[6] Ikegami, F., Fujii, Y., Ishihara, K. and Satoh, T. (2003) Toxicological aspects of Kampo medicines in clinical use. Chemical-Biological Interaction, 145, 235-250.

\section{doi:10.1016/j.tox.2004.01.029}

[7] Ikegami, F., Sumino, M., Fujii, Y., Akiba, T. and Satoh, T. (2006) Pharmacology and toxicology of Bupleurum root-containing Kampo medicines in clinical use. Human \& Experimental Toxicology, 25, 481-494. doi: $10.1177 / 0884533609342437$

[8] The Japanese Pharmacopoeia (2011) The Japanese Pharmacopoeia. 16th Edition, Hirokawa Publishing Co., Tokyo. http://jpdb.nihs.go.jp/jp16e/

[9] Kang, D. (2011) Resources of medicinal herbs: Considerations for the necessity of domestic production. Kampo \& the Newest Therapy, 20, 131-136.

[10] Ozaki, K., Shibano, M., Kusano G. and Watanabe, H. (2007) Aim for production of Glycyrrhizae Radix in Japan (1). A novel cultivation method of Glycyrrhiza uralensis Fisher. Shoyakugaku Zasshi, 61, 89-92.

[11] Ozaki, K., Shibano, M., Kusano, G. and Watanabe, H. (2010) Aim for production of Glycyrrhizae Radix in Japan (2). Selection of pharmaceutically fine strains from Glycyrrhiza uralensis Fisher. Shoyakugaku Zasshi, 64, 76-82.

[12] Jiho Editorial Department (2011) National Institute of 
Biomedical Innovation, Kajima Corporation and Chiba University developed the system for the stable domestic production of high-quality Glycyrrhiza uralensis (glabra). Pharmaceutical Technology Japan, 27, 2390.

[13] Ikegami, F., Kaneko, M., Tsukagoshi, S., Ito, T., Nagatsuka, T., Matsumoto, J. and Miyamoto H. (2008) Development of the cultivation system for organic herbal medicine. The 128th Annual Meeting of Pharmaceutical Society of Japan, 2, 57.

[14] Japan Speciality Agriculture Products Association (2007) Yakuyo-sakumotsu betsu Todoufuken Saibai Gaikyo, 18.

[15] Kaneko, M., Tsukagoshi, S., Yanagisawa, K., Yamada, M., Motoki, S., Hagihara, Y. and Ikegami, F. (2011) Effects of freezing of Swertia japonica seeds on germination, seedling yield and swertiamarin content. Shoyakugaku Zasshi, 65, 39-42.

[16] Yamada, M., Tsukagoshi, S., Yanagisawa, K., Kaneko, M., Motoki, S., Hagihara, Y. and Ikegami, F. (2011) Effects of strage temperature and gibberellin pretreatment on germination rate of Swertia japonica Seed. Horticultural Research (Japan), 10, 321-324.

[17] Kaneko, M., Tsukagoshi, S., Ikegami, F., Yanagisawa, K., Motoki, S. and Hagihara, Y. (2012) Effect of varieties, plant age and altitude of production site on swertiamarin content in Swertia japonica. Acta Horticulture, in press.

[18] Wang, Y., Sumino, M., Chino, A. and Ikegami, F. (2011) Study on a new decoction method of Kampo medicine by a microwave oven. Journal of Traditional Medicines, 28, 92.

[19] Ikegawa, K., Takayanagi, H. and Anan, T. (1990) Quantitative analysis of tea constituents, 7: Tannin. Tea Research Journal, 71, 52-53.

[20] Sumino, M., Saito, Y., Ikegami F. and Namiki T. (2011) Chemical analysis of the constituents in the residual crude drugs of shosaikoto. Journal of Traditional Medicines, 28, 75 .

[21] Tsukagoshi, S., Inuzuka, S., Hohjo, M., Ikegami, F., Takenaga, S., Nakao, C., Uryu, N., Hagiwara, T., Aoki, H. and Hanamura, T. (2011) Evaluation of Japanese radish cultivars in terms of medicinal properties for "Yakuzen" dishes. HortResearch, 65, 81-86.

[22] Tsukagoshi, S., Takano, A., Hohjo, M., Ikegami, F., Hagiwara, T., Nakao, C., Yamada, K., Hanamura, T., Takenaga, S. and Aoki, H. (2011) Evaluation of some local cultivars of carrot in terms of the suitability as materials for "Yakuzen" dishes. Journal of Traditional Medicines, 28, 106-114.

[23] Watanabe, K. (1988) Carotenoid pigments in red, orange and yellow root of carrot (Daucus carota L.) cultivars. Japan Journal of Food Engineering, 35, 315-320.

[24] Takahashi, A., Okushima, S., Kodama, H. and Yoshida, K. (2001) Constituent and sensory changes of different types of carrots after freezing and frozen storage. Food Preservation Science, 27, 119-132. doi:10.5891/jafps.27.119

[25] Kjeldsen, F., Christensen, L.P. and Edelenbos, M. (2001) Quantitative analysis of aroma compounds in carrot (Daucus carota L.) cultivars by capillary gas chromatography using large-volume injection technique. Journal of Agricultural Food Chemistry, 49, 4342-4348. doi:10.1021/jf010213n

[26] Kreutzmann, S., Thybo, A.K., Edelenbos, M. and Christensen, L.P. (2008) The role of volatile compounds on aroma and flavor perception in coloured raw carrot genotypes. Journal of Food Science Technology, 43, 16191627. doi:10.1111/j.1365-2621.2007.01662.x

[27] Nakamura, Y., Iwahashi, T., Tanaka, A., Koutani, J., Matsuo, T., Okamoto, S., Sato, K. and Ohtsuki, K. (2001) 4-(methylthio)-3-butenylisothiocyanate, a principal antimutagen in Daikon (Raphanus sativus; Japanese white radish). Journal of Agricultural Food Chemistry, 49, 57555760. doi: $10.1021 /$ if 0108415

[28] Hamano, E., Tsukagoshi, S., Hohjo, M. and Ikegami, F. (2009) Production of tomato fruits containing low potassium for kidney disease. 3. Potassium concentration in the fruits of some cultivars as affected by withdrawal of potassium in the nutrient solution. Horticultural Research (Japan), 8, 511 . 